\title{
I Consenso SOBEP de aspiração de crianças com tubo endotraqueal: a busca pela aproximação da ciência e da prática
}

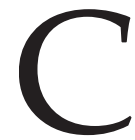
omo enfermeiros e profissionais da saúde, estamos vivendo em uma comunidade em que a produção e a publicação do conhecimento científico é eixo norteador. Entretanto, ainda percebemos uma lacuna entre o conhecimento científico produzido por meio do desenvolvimento de pesquisas e sua utilização na prática profissional. Esse contexto dificulta o desenvolvimento de uma prática baseada em evidências nos diversos cenários clínicos espalhados por todo o país. Muitas ainda são as barreiras que o enfermeiro necessita vencer para a utilização das melhores evidências das pesquisas em sua prática assistencial.

A enfermagem baseada em evidências é definida como o uso consciente, explícito e criterioso de informações derivadas da teoria, baseadas em pesquisas, para a tomada de decisão sobre o cuidado prestado a indivíduos ou grupo de pacientes, levando em consideração as necessidades individuais, as preferências ${ }^{(1)} \mathrm{e}$ o contexto local. Portanto, esta abordagem fundamenta-se no conhecimento e na qualidade da evidência com o propósito de promover a qualidade do cuidado de enfermagem e a diminuição de seus custos operacionais. ${ }^{(2)}$

A evidência científica pode ser caracterizada como um conjunto de informações que fornece provas para a tomada de decisão, abrangendo desde resultados de pesquisas a consensos de especialistas reconhecidos por sociedades científicas como a Sociedade Brasileira de Enfermeiros Pediatras (SOBEP). ${ }^{(3)}$ Embora saibamos que a utilização de práticas clínicas baseadas em evidências não garantam a certeza dos resultados, elas podem ajudar a minimizar danos e aumentar a eficiência profissional, produzindo melhores resultados de saúde. ${ }^{(4)}$ Neste sentido, a SOBEP adotou como meta o desenvolvimento de diretrizes clínicas e consensos com o intuito de recomendar práticas para aprimorar o cuidado de enfermagem prestado a neonatos, crianças, adolescentes e suas famílias.

As diretrizes clínicas baseadas em evidências são documentos informativos que incluem recomendações destinadas a otimizar o cuidado a criança e família e que são compostos por uma revisão sistemática das evidências e uma avaliação dos benefícios e malefícios de um cuidado. Já os consensos são documentos informativos que incluem recomendações destinadas a otimizar o cuidado a criança e família e que são compostos pela opinião de especialistas na área com base em revisões integrativas da literatura.

Em 2016, durante o XVIII Encontro Catarinense de Enfermagem Pediátrica (ECENPE) e I Jornada do Grupo de Ensino, Pesquisa e Extensão na Saúde da Criança e do Adolescente (GEPESCA), membros da SOBEP sob a coordenação da Comissão de Assistência da entidade discutiram temas prioritários e estratégias para elaboração de diretrizes e consensos para enfermeiros pediatras. Entre os 
temas elencados, priorizou-se a aspiração de crianças com tubo endotraqueal, visto constituir procedimento complexo comumente realizado.

Posteriormente, revisões integrativas da literatura foram realizadas em bases como SCOPUS, CINAHL, LILACS, PEDro, COCHRANE, utilizando inicialmente descritores e palavras-chave como Suction, Pediatrics, Suction cateter, Airway, Sputum, Airway secretion e Respiratory aspiration. A medida que elementos do processo de aspiração iam sendo identificados como por exemplo indicação, tempo de aspiração, número de repetições, novas revisões foram sendo realizadas para explorar o elemento identificado. $\mathrm{O}$ resultado das revisões foi apresentado a professores, gerentes e enfermeiros membros da SOBEP para discussão das evidências e recomendações da sociedade. Nesta edição da Revista SOBEP, apresentamos, então, o I Consenso SOBEP de aspiração de crianças com tubo endotraqueal.

Este consenso apresenta recomendações sobre questões como indicações e contraindicações, normas de biossegurança, características da sonda de aspiração, tempo de aspiração, pressão negativa, número de repetições, instilação de solução salina, hiperoxigenação, profundidade da aspiração e uso de aspiração em sistema aberto ou fechado. Estas recomendações estão baseadas no conhecimento científico mais atual a respeito deste tema e na opinião de especialistas membros da SOBEP.

O público alvo desse consenso são enfermeiros pediatras, gestores de enfermagem, acadêmicos de enfermagem e demais envolvidos direta ou indiretamente no cuidado à criança com indicação de aspiração endotraqueal. O objetivo deste documento é orientar o enfermeiro pediatra na tomada de decisão sobre a aspiração endotraqueal e guiar a construção de protocolos de cuidado para uniformização da assistência e adaptação das recomendações à realidade local.

Esperamos que esta nova abordagem de aproximação de ciência e prática permita aos enfermeiros pediatras maior segurança na aplicação de seu cuidado. Subsidie ainda informações para torná-los capazes de melhorar os resultados de saúde das crianças e consequentemente maior satisfação dos pais em relação ao trabalho de enfermagem.

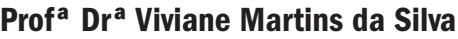
Universidade Federal do Ceará, Fortaleza, CE, Brasil Presidente da Comissão Permanente de Assistência da SOBEP https://orcid.org/0000-0001-6339-5167

DOI: http://dx.doi.org/10.31508/1676-3793201800009

\section{Referências}

1. Atallah AN, Castro AA. Fundamentos da pesquisa clínica. São Paulo: Lemos Editorial; 1998.

2. Ingersoll GL. Evidence-based nursing: what it is and what it isn't. Nurs Outlook. 2000;48(4):151-2.

3. Pedrosa KK, Oliveira IC, Feijão AR, Machado RC. Enfermagem baseada em evidência: caracterização dos estudos no Brasil. Cogitare Enferm. 2015;20(4):733-41.

4. Galvão CM, Sawada N0, Rossi LA. A prática baseada em evidências: considerações teóricas para sua implementação na enfermagem perioperatória. Rev Latino-Am Enfermagem. 2002;10(5):690-5. 